\title{
Article \\ Reliability of Commercial UVC LEDs: 2022 State-of-the-Art
}

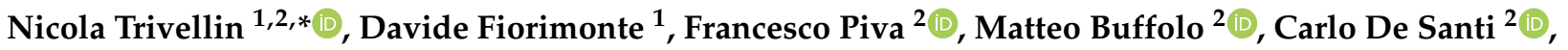 \\ Gaudenzio Meneghesso $^{2}$ D, Enrico Zanoni ${ }^{2}$ and Matteo Meneghini ${ }^{2}$ (D) \\ 1 Department of Industrial Engineering, University of Padova, Via Gradenigo 6A, 35131 Padova, Italy; \\ davide.fiorimonte@studenti.unipd.it \\ 2 Department of Information Engineering, University of Padova, Via Gradenigo 6B, 35131 Padova, Italy; \\ francesco.piva@unipd.it (F.P.); matteo.buffolo@dei.unipd.it (M.B.); carlo.desanti@unipd.it (C.D.S.); \\ gaudenzio.meneghesso@unipd.it (G.M.); enrico.zanoni@unipd.it (E.Z.); matteo.meneghini@unipd.it (M.M.) \\ * Correspondence: nicola.trivellin@unipd.it
}

check for updates

Citation: Trivellin, N.; Fiorimonte, D.; Piva, F.; Buffolo, M.; De Santi, C.; Meneghesso, G.; Zanoni, E.; Meneghini, M. Reliability of Commercial UVC LEDs: 2022 State-of-the-Art. Electronics 2022, 11, 728. https://doi.org/10.3390/ electronics 11050728

Academic Editor:

Nagarajan Raghavan

Received: 27 January 2022

Accepted: 22 February 2022

Published: 26 February 2022

Publisher's Note: MDPI stays neutral with regard to jurisdictional claims in published maps and institutional affiliations.

Copyright: (c) 2022 by the authors. Licensee MDPI, Basel, Switzerland. This article is an open access article distributed under the terms and conditions of the Creative Commons Attribution (CC BY) license (https:// creativecommons.org/licenses/by/ $4.0 /)$.

\begin{abstract}
With this study, we report on the reliability of the most recent commercial UVC LED devices. The current COVID-19 pandemic urged the development of antiviral technologies, and one of the most effective is based on UVC irradiation, which can be effectively achieved by means of Deep UV LEDs. The development of antiviral systems based on UVC LEDs strongly depends on their efficacy and reliability. We propose an in-depth analysis of four different state-of-the-art commercial LEDs suitable for disinfection applications. LEDs have been subjected to a controlled stress test near their application limits, and their reliability and characteristics have been analyzed and studied. Results indicate a still limited reliability, with a degradation possibly related to an increase in Shockley-Read-Hall (SRH) recombination. Finally, some relevant product design suggestions will be proposed based on the results of this work.
\end{abstract}

Keywords: UVC; LED; degradation; reliability; disinfection

\section{Introduction}

The recent global pandemic state caused by the SARS-CoV-2 virus has brought great attention to antiviral technologies. Ultraviolet, in the last decade, has been one of the most important technologies [1] to reliably inactivate viruses, bacteria, molds and a wide range of micro-organisms. As of 2022, we can present two main technologies for the generation of UVC radiation (below $300 \mathrm{~nm}$ ), i.e., discharge lamps (such as low-pressure mercury tube lamps) and solid-state devices (in particular LEDs). The advantages of the UVC LEDs are: miniaturization, improved efficacy and robustness. Differently from blue-emitting LEDs, which are based on an indium gallium nitride compound semiconductor, Deep UV (DUV) LEDs require a wider bandgap, which is achieved by means of the ternary compound aluminum gallium nitride. Due to the increase in market demand, UVC LEDs are produced and commercialized by several manufacturers to achieve higher-energy photons, and have been available on the market for at least a decade, but efficiency and price only just reached levels compatible with commercial applications. By means of UVC LEDs' small size and controlled emission, it is possible to uniformly irradiate objects, guaranteeing a minimum irradiance to treat the entire surface, but without exceeding the critical irradiance which can damage the surface of the treated material.

The reliability of UVC LEDs is probably the main limiting factor in their mass adoption. Even if it is true that a few minutes of irradiation can be sufficient to achieve a log 4 reduction of SARS-CoV-2 [2], thus meaning that several thousand disinfections can be achieved by an LED device, their use in continuous disinfection systems, such as water treatment plants, is still not advisable due to their limited lifetime (a few thousand hours according to manufacturers' datasheets).

The current state of the research indicates that the gradual degradation of UVC LEDs can be ascribed to different causes, and we report the main ones in the following. 
1. Modifications in the semiconductor material, such as: (i) Extension of the depletion region into the p-type region due to p-type carriers' compensation [3]. (ii) Increase in the dislocation density as a function of the operating current density [4]. (iii) Generation of non-radiative recombination centers in the active region of the device, possibly related to $\mathrm{Mg}$ acceptors and nitrogen vacancies [3,5,6]. (iv) Gallium vacancies related to the departure of unintentionally doped magnesium in correspondence with threading dislocations [7]. (v) Electron traps possibly associated with a $\mathrm{N}_{\mathrm{Ga}}$ antisite [8] that could reduce the confinement in the QW region, thus leading to an electron overspill due to a reduced blocking of the barrier [9]. (vi) Impurity displacement related to the carrier redistribution process in multiple quantum wells, especially for wells closer to the substrate [10].

2. Processing of the epistructure and structure of metal contacts, for example: (i) diffusionrelated mechanisms of impurities moving from the contact metal into the active region [11], (ii) metal electromigration causing leakage paths [12] and (iii) the role of a thick $\mathrm{Al}$ layer in a $\mathrm{Cr} / \mathrm{Al} / \mathrm{Ti} / \mathrm{Au}$ reflective n-type electrode on the reliability of AlGaN-based flip-chip DUV LEDs, which can be responsible for bulges and cracks, thus allowing the diffusion of contaminants into the device structure [13].

3. Packaging, such as the transmittance decay of silicone encapsulation as opposed to quartz glass airtight packaging [14] after DUV irradiation or the degradation of packaging resins [15].

Besides the reliability analysis and lifetime estimation reported in the scientific literature, semiconductor manufacturers have improved the quality and performance of commercial UVC LED in recent years. However, no in-depth analysis of the current status of the reliability of commercial UVC LEDs is available. The aim of this work is to provide a detailed comparison between UVC LEDs fabricated by different manufacturers and with different characteristic in order to estimate their lifetime and thus provide insight on: (i) the possible cause of the reliability issues, (ii) the average expected lifetime of the tested devices and (iii) provide a suggested use case scenario and best practices for the design of systems based on commercial UVC LEDs.

\section{Materials and Methods}

A summary of the properties of the UVC LEDs selected for the reliability test and analysis are reported in Table 1. Each LED has been selected from a different manufacturer and with different electrical and optical characteristics in order to assess the effect of different structures. In order to provide a faster analysis, a single LED for each category has been analyzed in this work, while upcoming works will analyze LEDs stressed at different conditions and with a higher number of samples. All the samples are SMD (Surface Mount Device) and have a flat quartz-based window, with the LED flip-chip installed in all the packages.

The experimental setup was composed of a source meter Keithley 2612, a photodiode Thorlabs PM100 and a spectrometer Instrument System CAS 140 CT. During the stress, the devices were placed on a thermo-electric plate controlled by an Arroyo TEC 5310. Electrical (Current Voltage I-V) and optical characterization (OP vs. current) were performed at each step of stress at different temperatures, from 15 to $75^{\circ} \mathrm{C}$ with steps of $10{ }^{\circ} \mathrm{C}$, whereas the PSD (Power Spectral Density) characterization was carried out only before and after the stress, at room temperature. 
Table 1. UVC LED characteristics.

\begin{tabular}{|c|c|c|c|c|c|c|c|}
\hline LED & $\begin{array}{c}\text { Absolute } \\
\text { Maximum } \\
\text { Current (A) }\end{array}$ & $\begin{array}{c}\text { Peak } \\
\text { Wavelength } \\
\text { (nm) }\end{array}$ & $\begin{array}{l}\text { Chip Size } \\
\left(\mathrm{mm}^{2}\right)\end{array}$ & $\begin{array}{l}\text { Package Size/ } \\
\text { Total Pad Area }\end{array}$ & $\begin{array}{l}\text { Nominal OP at } \\
\text { Current (mW } \\
@ \mathrm{~mA})\end{array}$ & $\underset{(\mathrm{k} / \mathrm{W})}{\mathrm{Rth}}$ & $\begin{array}{l}\text { Estimated } \\
\text { Price } \\
\text { (USD \$) }\end{array}$ \\
\hline A & 0.8 & 275 & 1 & $\begin{array}{c}\left.\text { SMD } 3.5 \times 3.5 \mathrm{~mm}^{2}\right) \\
\text { Thermal Pad }\left(4.9 \mathrm{~mm}^{2}\right) \\
\text { Contacts }\left(3.15 \mathrm{~mm}^{2}\right)\end{array}$ & $\begin{array}{l}37.5 \mathrm{~mW} \\
@ 350 \mathrm{~mA}\end{array}$ & 5 & 24.06 \\
\hline B & 0.3 & 277 & 0.25 & $\begin{array}{l}\text { SMD } 3.5 \times 3.5 \mathrm{~mm} \\
\text { No Thermal Pad } \\
\text { Contacts }\left(4.19 \mathrm{~mm}^{2}\right)\end{array}$ & $\begin{array}{c}12 \mathrm{~mW} \\
\text { @ } 100 \mathrm{~mA}\end{array}$ & 24 & 3.99 \\
\hline C & 0.1 & 278 & 0.21 & $\begin{array}{c}\left.\text { SMD } 3.6 \times 3.6 \mathrm{~mm}^{2}\right) \\
\text { Thermal Pad }\left(3.4 \mathrm{~mm}^{2}\right) \\
\text { Contacts }\left(6.12 \mathrm{~mm}^{2}\right)\end{array}$ & $\begin{array}{c}5 \mathrm{~mW} \\
@ 50 \mathrm{~mA}\end{array}$ & 45 & 5.87 \\
\hline $\mathrm{D}$ & 0.15 & 278 & 0.3 & $\begin{array}{c}\text { SMD } 3.9 \times 3.9 \mathrm{~mm}^{2} \\
\text { Thermal Pad }\left(4.5 \mathrm{~mm}^{2}\right) \\
\text { Contacts }\left(3.9 \mathrm{~mm}^{2}\right)\end{array}$ & $\begin{array}{c}10 \mathrm{~mW} \\
@ 150 \mathrm{~mA}\end{array}$ & 15 & 29 \\
\hline
\end{tabular}

The stress current for each LED was chosen as the maximum current indicated in the manufacturer's datasheet in order to stress the devices close to the application limits. During the stress procedure and the measurement tests, the LED board was set at a temperature of $25^{\circ} \mathrm{C}$, and from the provided thermal resistance, the junction temperature was estimated as: $61{ }^{\circ} \mathrm{C}$ for LED A, $55.6^{\circ} \mathrm{C}$ for LED B and $54.25^{\circ} \mathrm{C}$ for LED C, from the datasheet provided. On the other hand, the parameters for electrical, optical and spectral characterization were chosen according to the relative characteristics of the devices, in order to not stress the samples during these measurements. The complete set of experimental conditions are reported in Table 2.

Table 2. Summary of the experimental details.

\begin{tabular}{ccccc}
\hline Device & Stress Current (A) & $\begin{array}{c}\text { I-V, from (V) to (V), with Step of } \\
\mathbf{0 . 0 5} \mathbf{~ V , ~ a n d ~ C o m p l i a n c e ~ o f ~ ( A ) ~}\end{array}$ & $\begin{array}{c}\text { OP vs. Current, from (A) to } \\
\text { (A) with Logarithmic Steps }\end{array}$ & PSD-I at (A) \\
\hline A & 0.8 & $-5,11,0.5$ & $5 \times 10^{-6}, 0.5$ & $0.0001,0.001,0.01,0.1$ \\
B & 0.3 & $-5,11,0.25$ & $1 \times 10^{-5}, 0.25$ & $0.0001,0.001,0.01,0.1$ \\
C & 0.1 & $-5,9,0.05$ & $5 \times 10^{-6}, 0.05$ & $0.0001,0.001,0.01,0.05$ \\
D & 0.15 & $-5,9,0.1$ & $5 \times 10^{-6}, 0.1$ & $0.0001,0.001,0.01,0.05$ \\
\hline
\end{tabular}

\section{Results}

In this section, we report the results of the electrical, optical and spectral characterization carried out before, after and during the reliability analysis.

\subsection{Electrical Characterization}

Figure 1 reports the I-V characteristics in log and linear scale for the five samples before and after the ageing test. It can be observed that all of the samples showed some increase in the current in the generation/recombination region in forward bias in the voltage region between 1 and $4 \mathrm{~V}$. Only sample A was analyzed in reverse bias since it is not equipped with a reverse protection diode: results also indicate a current increase in this condition.

The gradual variation in the low-bias forward current and the reduction in the series resistance has been plotted in Figure 2, and it can be observed that samples A and C had a gradual increase in the low-bias voltage of $4-5$ times the initial value, while samples $B$ and E's electrical characteristics at low forward bias were less affected by the degradation, even if a lower variation was still noticeable. LED D, instead, showed a gradual initial decrease in the current, with a subsequent rapid and massive increase. 


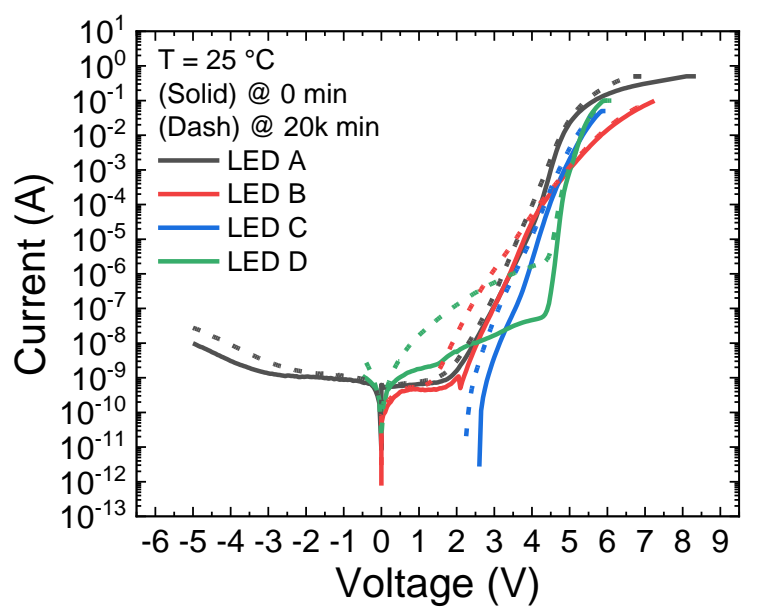

(a)

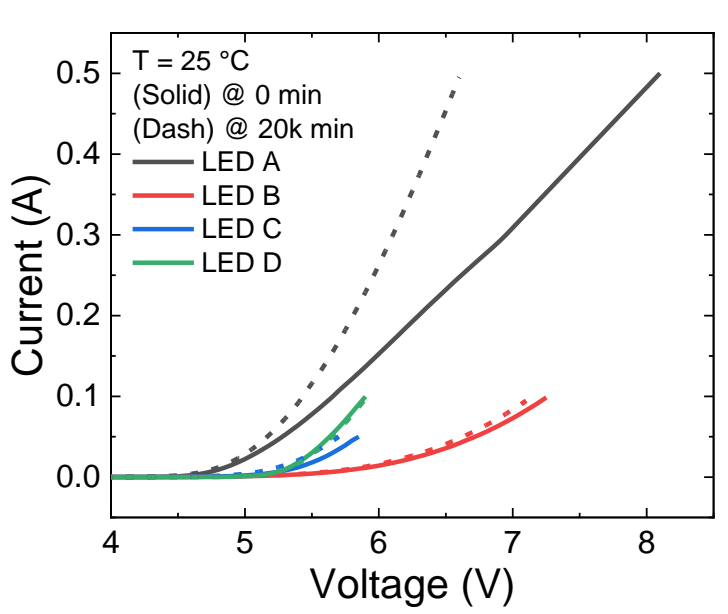

(b)

Figure 1. Current vs. voltage characteristics before and after 20,000 min of stress: (a) semi-log scale and (b) linear scale.

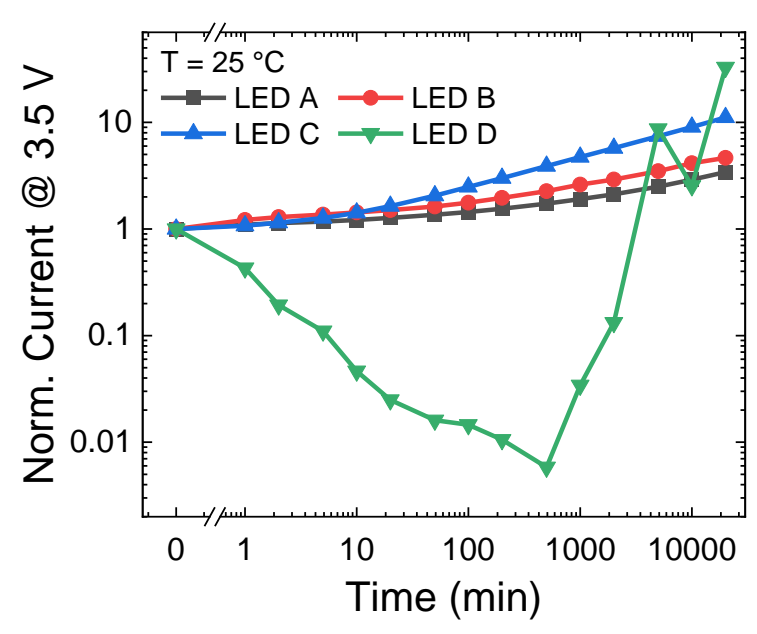

(a)

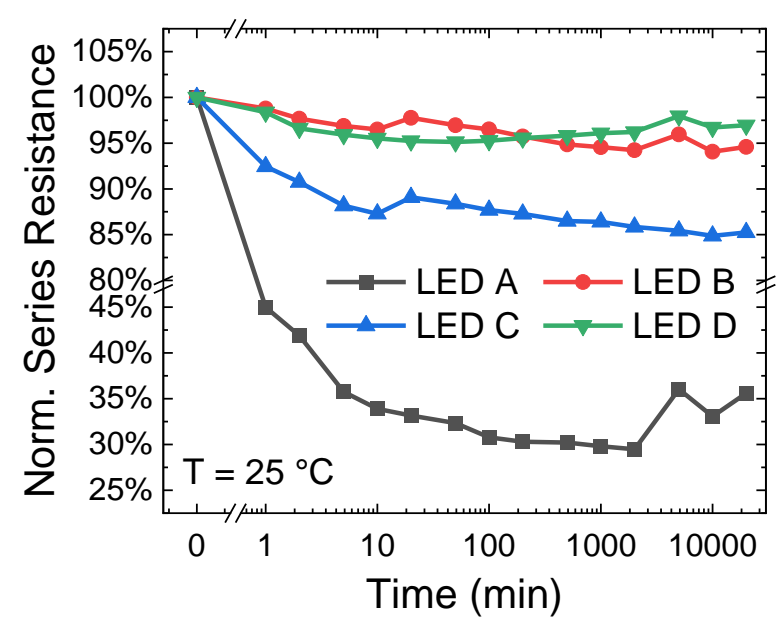

(b)

Figure 2. Subthreshold current and series resistance plots during the stress tests: (a) normalized current at low bias and (b) normalized series resistance.

In the right plot of Figure 2, it is possible to observe the variation in the series resistance of all the LEDs during the reliability test. While LED B and D series resistance was almost not affected, LED C showed a gradual decrease in the series resistance to approximately $85 \%$ of its initial value. LED A instead showed a strong variation (approximately a $50 \%$ decrease) in the first minutes of stress and then a gradual variation compatible with the latter LED.

The increase in the current at low forward and reverse bias and the reduction in the forward voltage, which is confirmed by the gradual reduction in the series resistance, is compatible with an increase in localized defects resulting in significant generation of parasitic shunt paths, as proposed in [16] for InGaN LEDs or in [12] for DUV LEDs. The abrupt variation of LED D in low forward bias can be explained by an initial higher generation/recombination current, possibly related to initial defects, followed by an abrupt increase of the parallel shunt conduction component, possibly related to a lateral passivation leakage [17-20]. The sudden decrease in series resistance of sample A could be ascribed to an ohmic contact annealing [21,22], or another mechanism related to passivation of electrical defects. 


\subsection{Optical Characterization}

The results of the optical measurements carried out during the reliability test are reported in Figures 3 and 4 . In the left plot of Figure 3, it is possible to study the effect of the 20,000 min stress test on the emitted optical power (OP) of the samples. It can also be observed that initially, the LEDs have a similar performance, and even if they have a different chip size, the OP vs. current slope is comparable between the different samples.

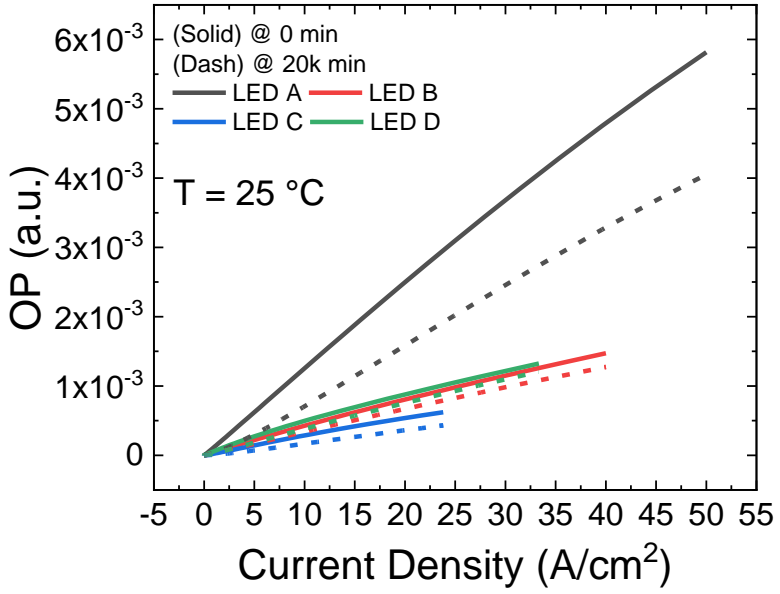

(a)

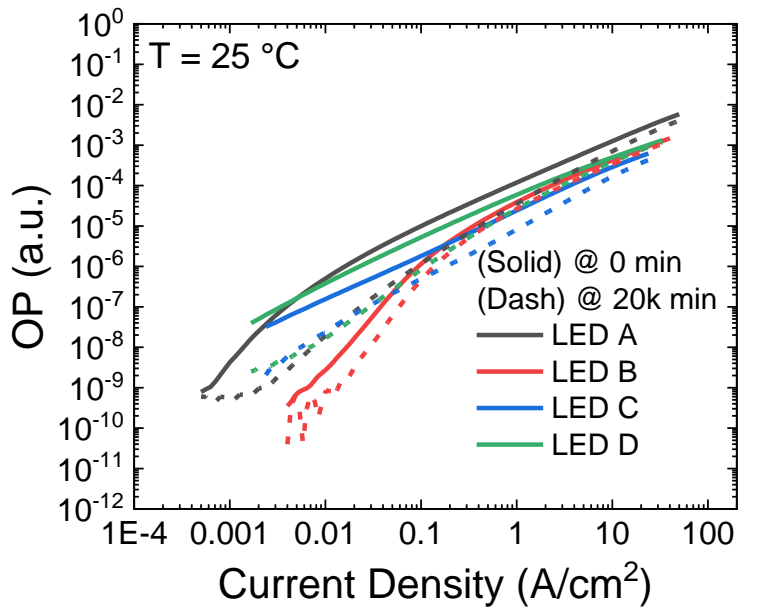

(b)

Figure 3. Optical power vs. current characteristics before and after 20,000 min of stress: (a) linear scale and (b) $\log$ scale.

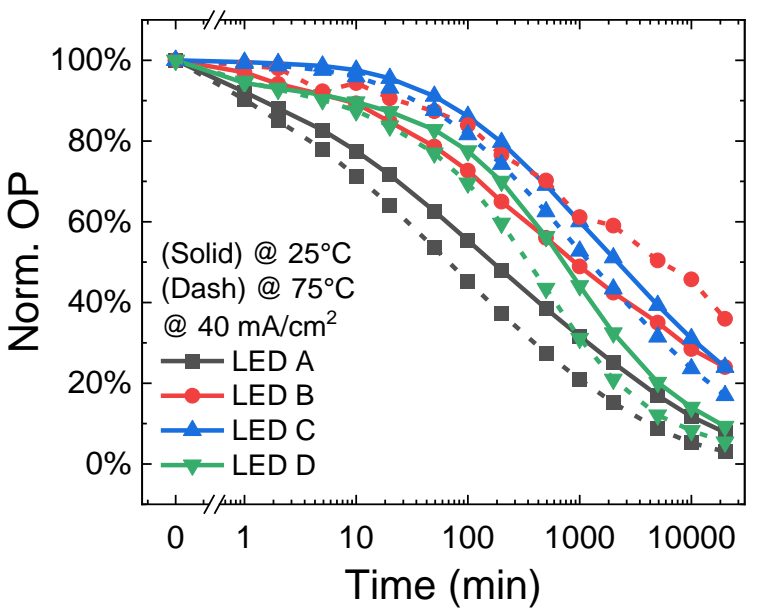

(a)

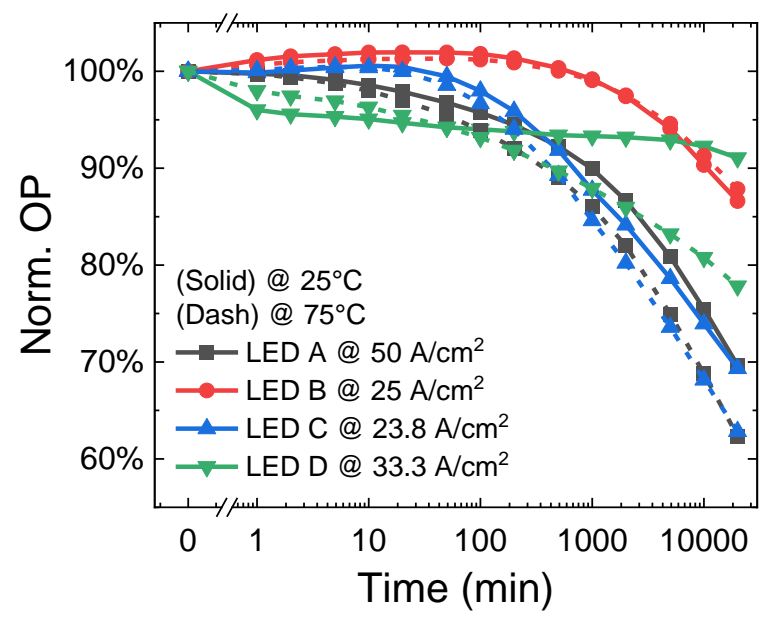

(b)

Figure 4. Variation in the OP during the reliability test, carried out at low (a) and high (b) current and measured at two different temperatures $\left(25\right.$ and $\left.75^{\circ} \mathrm{C}\right)$.

All the LEDs reported a decrease in the emitted OP after the stress. In the right plot of Figure 3, we reported the log scale of the OP vs. current characteristic of the LEDs, and it can be clearly noticed that while LED $\mathrm{C}$ and $\mathrm{D}$ had a linear behavior also at low currents, LED A and B suffered from a reduction of emitted optical power at currents below $200 \mu \mathrm{A}$. After the degradation, all of the LEDs demonstrated a stronger decrease of performance at low currents than in the high-current regime.

To analyze the kinetics of the OP variation during the ageing, we plotted the normalized OP variation at the low current (the same current density for all LEDs) and at the nominal current (which is stated by the manufacturer and also related to the device die 
area), respectively, in the left and right plots of Figure 4. It can be observed that all the LEDs suffered from a more prominent degradation at a lower measuring current with respect to the nominal current. Samples A and D suffered from a higher decrease in OP at low currents, reaching nearly zero emission after 20,000 min. The higher decrease in the OP at the lower measurement current can be related to the generation of SRH recombination centers located in the active region: they are responsible for a non-radiative recombination carrier loss, which is relatively more impactful at low currents, since at a high carrier concentration, the recombination through defect states starts to saturate.

Results also indicate that all the LEDs, apart from LED B, suffered a higher reduction in the OP when biased at a high current; for LED B, the degradation was independent of measurement temperature. Particularly interesting is LED D, which showed a lower degradation when measured at $25^{\circ} \mathrm{C}$, but a degradation similar to the other LEDs when measured at a temperature of $75^{\circ} \mathrm{C}$. This result also indicates that the stressed devices showed an increased thermal droop $[23,24]$, thus indicating a possible confirmation of the $\mathrm{SRH}$ recombination increase or a reduction in carrier confinement due to trap/thermally assisted barrier escape [25].

We have also analyzed the slopes of the log-log optical power-current density graph, as reported in Figure 5, for the two LEDs that did not show a parasitic peak with a height comparable to the main peak at low current levels (see Figure 6).

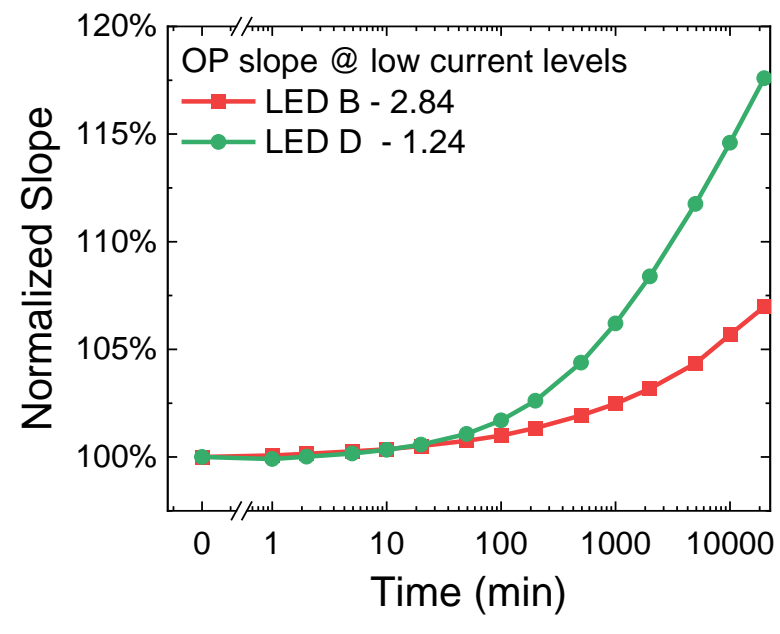

(a)

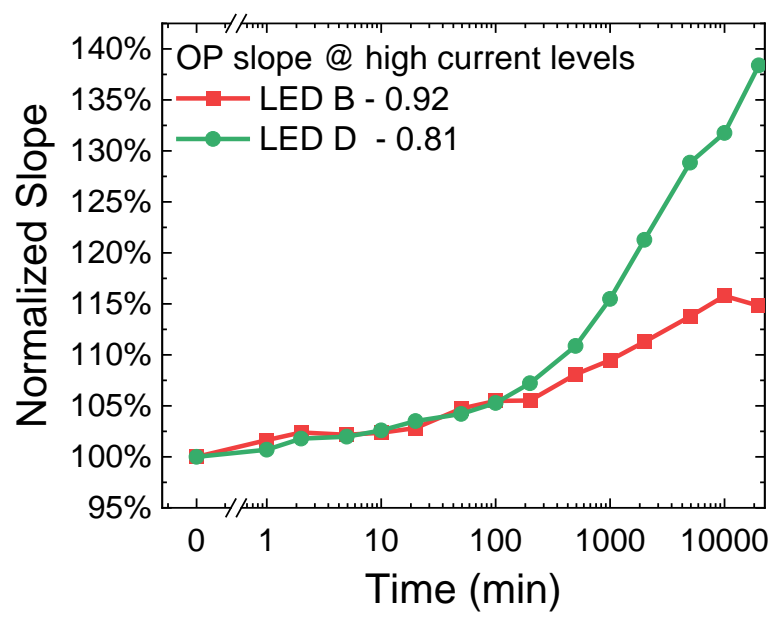

(b)

Figure 5. Variation in the slopes of the optical power during the reliability test, measured at low (a) and high (b) current levels, at $25^{\circ} \mathrm{C}$. Absolute slope initial value is reported in the legend near the device name.

We noticed a slope close to 1 at the high current level, which is an indicator of a regime where the radiative recombination prevails [26]. For LED B and D, the slopes increased with stress time, indicating a stronger contribution of non-radiative recombination processes also in high carrier injection conditions. At low current levels, LED B had a slope of about 2, indicating a regime where non-radiative recombination prevails [27,28]. LED D showed a lower slope but it presented the highest increase, which could be ascribed to a stronger generation of non-radiative centers in the device [28]. The same behavior could be found in the other two LEDs, indicating that optical degradation may be partially correlated to a defect generation. 


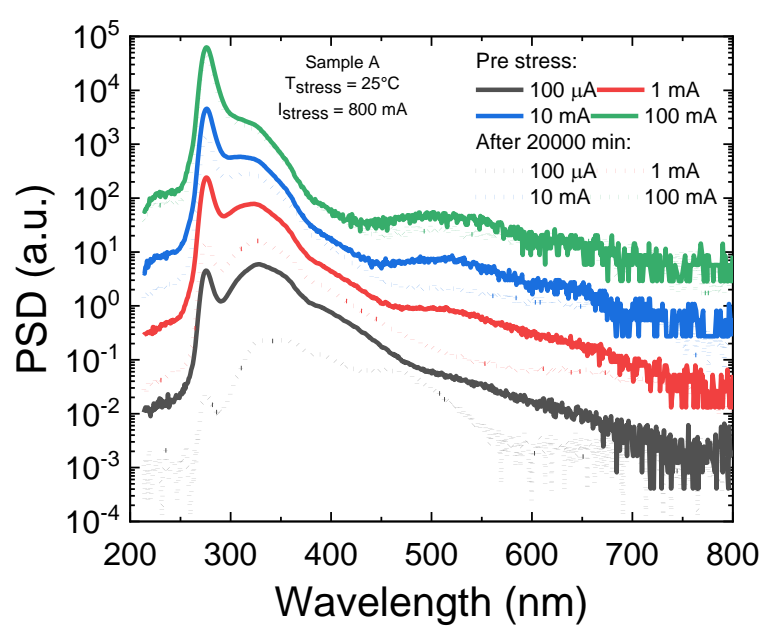

(a)

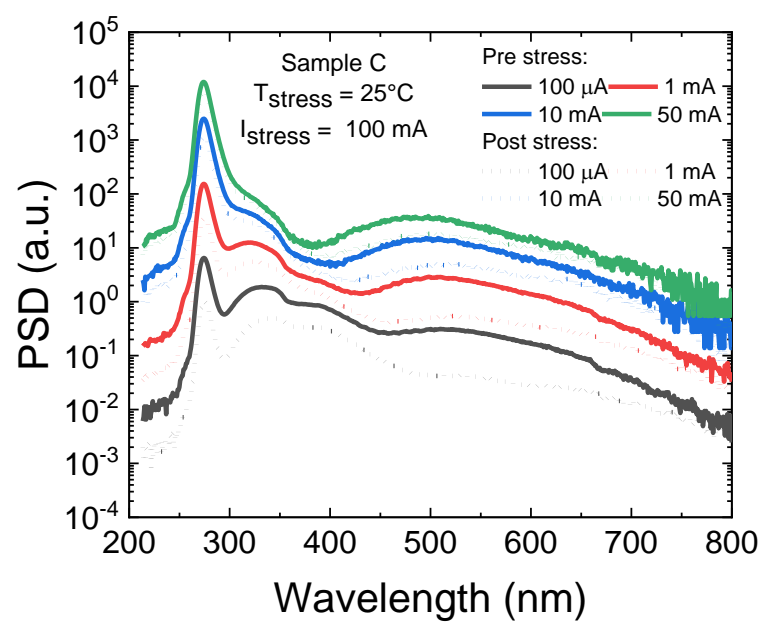

(c)

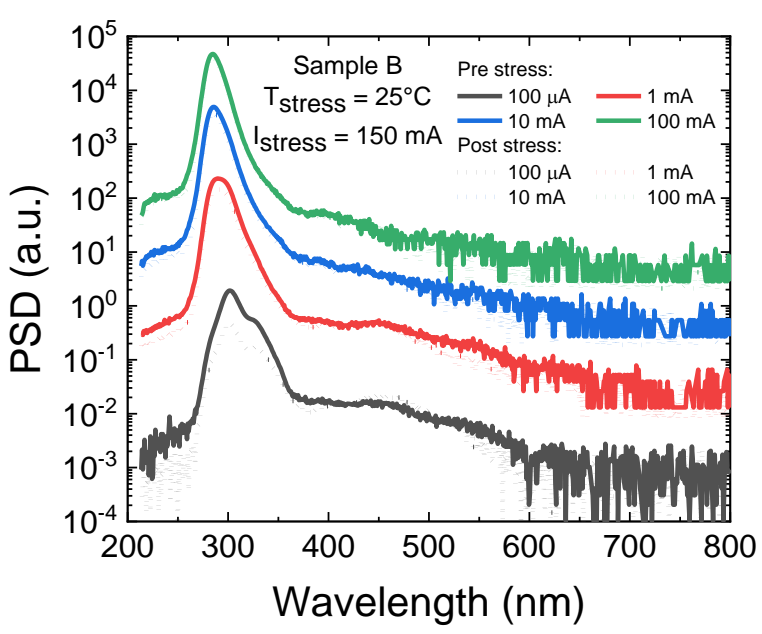

(b)

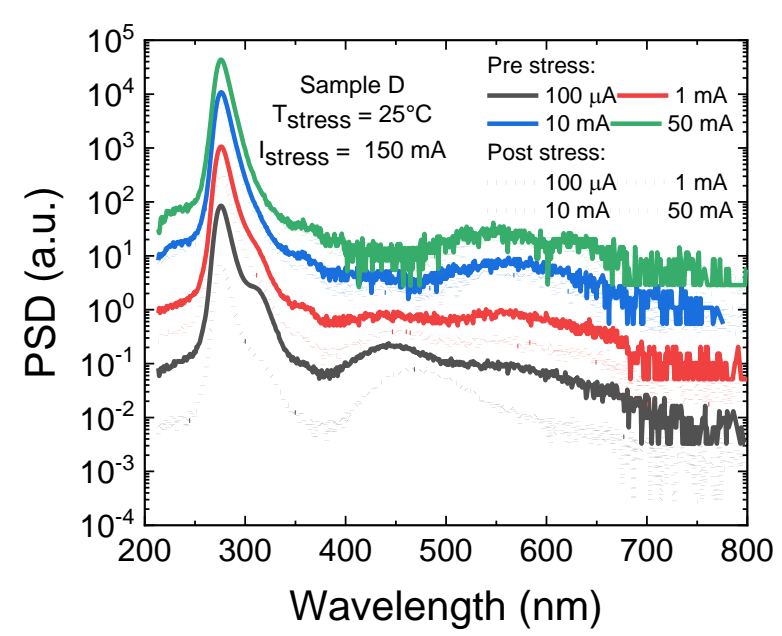

(d)

Figure 6. Spectrum of the samples before and after the stress test, measured at different currents: (a) sample A, (b) sample B, (c) sample C and (d) sample D.

\subsection{Spectral Characterization}

As described in our previous work [25], specifically focused on parasitic luminescence of DUV LEDs, the analysis of the spectrum is fundamental to understand the different recombination mechanisms taking place during device ageing. The spectrum emissions of the LEDs before and after the stress procedure are reported in Figure 6.

All the UVC LEDs analyzed in this work showed a gradual decrease in the main emission peak as a consequence of the degradation; however, each LED had a different kinetic regarding the parasitic peaks. LED A had a broad shoulder peak at around $350 \mathrm{~nm}$ : during the degradation, the peak decreased, but its variation was lower than that of the main peak, and a broad peak at $475 \mathrm{~nm}$ became visible at the lowest measurement current. Both of these peaks could be due to recombination events outside the quantum well, possibly assisted by defects $[29,30]$. It can also be noticed that at high current levels, a broad band in the range from 500 to $600 \mathrm{~nm}$ appeared, which can possibly be ascribed to the typical yellow luminescence band of GaN [31]. The LED B parasitic spectrum was almost not affected by the degradation, and only at a low current was it possible to observe a parasitic band at $475 \mathrm{~nm}$ and a shoulder peak at about $350 \mathrm{~nm}$, the former of which tended to increase during stress with respect to the main emission. Similar to LED A, LED C showed a less intense reduction in the shoulder peaks with respect to 
the main peak; in general, the very broad parasitic peak at 500-600 $\mathrm{nm}$ reduced during degradation. LED D showed a decrease in the main peak and a decrease in the shoulder peak, and additionally in this case a new broad peak arose at around $475 \mathrm{~nm}$ at the lowest measurement current. A recurring trend of most of the LEDs under investigation was the presence of two or more parasitic peaks/bands at similar wavelengths, in particular at about 350, 475 and 500-600 nm, indicating similar design and/or growth or processing in all devices. Moreover, since they are only noticeable at low currents, most of them are probably not related to carrier overspill through the barrier, but more probably to radiative defect transitions, as already reported in previous works [29]. Under this assumption, finding the same parasitic peaks in all devices is expected, since it is related to the presence and/or generation of the same defects in all the samples.

\section{Discussion}

By comparing the results achieved on the tested samples, we can observe a good stability of the electrical characteristics with some degradation effects at lower currents, possibly related to SRH recombination. The decrease of the OP during degradation when the devices were stressed at their maximum allowed current was significant, and in Figure 7 we can observe a histogram reporting a summary of the reliability-related parameters for the measured LEDs.

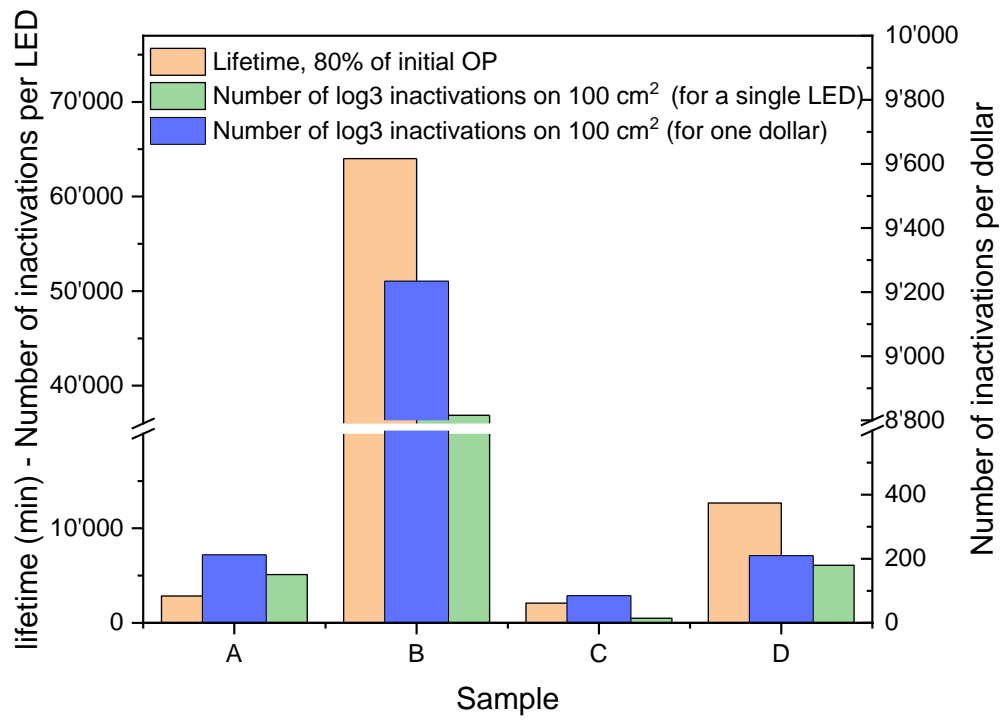

Figure 7. Summary of tested LEDs' lifetime at $80 \%$ of initial optical power after stress at maximum current. Measurement carried out at $75^{\circ} \mathrm{C}$. The value for LED B has been extrapolated by data projection from single exponential fit.

The first part of the plot (orange bars) relates to the lifetime of the LEDs calculated at $80 \%$ of their initial OP, when measured at a temperature of $75^{\circ} \mathrm{C}$ (compatible with real operating conditions). The green bars of the plot relate to the number of SARS-CoV-2 $99.9 \%(\log 3)$ treatments that can be achieved with a single LED on a surface of $100 \mathrm{~cm}^{2}$ during the lifetime of the device (a minimum dose of $10 \mathrm{~mJ} / \mathrm{cm}^{2}$ is required to reach a $\log 3$ inactivation [1]), corresponding to $1 \mathrm{~J}$ over an area of $100 \mathrm{~cm}^{2}$. For each LED, $80 \%$ of the initial optical power was considered. The blue bars of the plot report the number of virucide treatments that can be achieved normalized to the cost of the device (number of inactivation per dollar). It should be noted that important differences in reliability can be seen between the LEDs: the lifetime - under the extremely high-stress conditions adopted-ranged from $2000 \mathrm{~min}(\sim 33 \mathrm{~h})$ for LED C to $64,000 \mathrm{~min}(\sim 1000 \mathrm{~h})$ for LED B. However, due to the low energy required for a single inactivation, during the lifetime of the devices they are able to guarantee thousands of treatments. An interesting result was obtained when factoring the cost of the emitters with respect to their useful life. Results indicate that for LED A, C and D, 
the different price somewhat normalizes their cost of operation, while the low price of LED $\mathrm{B}$, together with its reliability, further separates its result, bringing nearly a 50-fold advance over its competitors. LED B, in terms of reliability, outscores other devices even if it is not the most powerful sample. For this device, it should be noticed that it has a much lower emission in the higher wavelengths as compared to other LEDs (see Figure 6b), and this characteristic probably indicates a better semiconductor quality [25]. Future works based on deep-level spectroscopy will be carried out on this set of samples to further investigate their properties.

\section{Conclusions}

Summarizing the results, it is quite clear that the reliability of commercially available UVC LEDs emitting at 270-280 $\mathrm{nm}$ and stressed near their absolute maximum current is, in 2022, still quite limited. It can be observed, however, that by comparing the results summarized in the present work with the dose required to achieve an antiviral effect on SARS-CoV-2 virus [1], a single treatment can require a few minutes; thus, the lifetime of these devices may still be sufficient for thousands of operations.

In conclusion, from the presented work, we can extract some important knowledge which can be crucial when designing an electronic system based on UVC LEDs:

- The degradation of UVC LEDs is possibly related to generation of defects in the active area of the device, which results in increasing $\mathrm{SRH}$ recombination.

- The reliability of current UVC LEDs varies based on the manufacturer and device quality.

- The performance of a system should consider a gradual decrease of the optical power emitted from the LEDs.

- The degradation is more prominent at high temperatures and low currents, so care must be taken in the design of systems, also depending on the expected operating conditions.

Author Contributions: Conceptualization, N.T., M.M., M.B. and C.D.S.; methodology, N.T. and M.M.; experimental investigation, D.F. and F.P.; data curation, N.T. and F.P.; writing-original draft preparation, N.T. and F.P.; writing—review and editing, N.T., M.M., M.B. and C.D.S.; supervision, N.T., M.M., G.M. and E.Z. All authors have read and agreed to the published version of the manuscript.

Funding: This research received no external funding.

Data Availability Statement: The data presented in this study are available upon request from the corresponding author. The data are not publicly available due to non-disclosure confidentiality agreements.

Acknowledgments: The work at University of Padova was partly performed within project Internet of Things: Sviluppi Metodologici, Tecnologici e Applicativi, co-founded (2018-2022) by the Italian Ministry of Education, Universities and Research (MIUR), under the aegis of the "Fondo per il finanziamento dei dipartimenti universitari di eccellenza" initiative (Law 232/2016).

Conflicts of Interest: The authors declare no conflict of interest.

\section{References}

1. Trivellin, N.; Piva, F.; Fiorimonte, D.; Buffolo, M.; De Santi, C.; Orlandi, V.T.; Dughiero, F.; Meneghesso, G.; Zanoni, E.; Meneghini, M. Uv-based technologies for sars-cov2 inactivation: Status and perspectives. Electronics 2021, 10, 1703. [CrossRef]

2. Trivellin, N.; Buffolo, M.; Onelia, F.; Pizzolato, A.; Barbato, M.; Orlandi, V.T.; Del Vecchio, C.; Dughiero, F.; Zanoni, E.; Meneghesso, G.; et al. Inactivating SARS-CoV-2 Using 275 nm UV-C LEDs through a Spherical Irradiation Box: Design, Characterization and Validation. Materials 2021, 14, 2315. [CrossRef]

3. Moe, C.G.; Reed, M.L.; Garrett, G.A.; Sampath, A.V.; Alexander, T.; Shen, H.; Wraback, M.; Bilenko, Y.; Shatalov, M.; Yang, J.; et al. Current-induced degradation of high performance deep ultraviolet light emitting diodes. Appl. Phys. Lett. 2010, 96, 213512. [CrossRef]

4. Khan, A.; Seongmo, H.; Lowder, J.; Adivarahan, V.; Fareed, Q. Reliability issues in AlGaN based deep ultraviolet light emitting diodes. In Proceedings of the 2009 IEEE International Reliability Physics Symposium, Montreal, QC, Canada, 26-30 April 2009; pp. 89-93. [CrossRef]

5. Sawyer, S.; Rumyantsev, S.L.; Shur, M.S. Degradation of AlGaN-based ultraviolet light emitting diodes. Solid. State. Electron. 2008, 52, 968-972. [CrossRef] 
6. Nakarmi, M.L.; Nepal, N.; Lin, J.Y.; Jiang, H.X. Photoluminescence studies of impurity transitions in Mg-doped AlGaN alloys. Appl. Phys. Lett. 2009, 94, 10-13. [CrossRef]

7. Wang, Y.-Z.; Zheng, X.-F.; Zhu, J.-D.; Xu, L.-L.; Xu, S.-R.; Liang, R.-L.; Dai, J.-N.; Li, P.-X.; Zhou, X.-W.; Mao, W.; et al. Degradation in AlGaN-based UV-C LEDs under constant current stress: A study on defect behaviors. Appl. Phys. Lett. 2020, 116, 203501. [CrossRef]

8. Pinos, A.; Marcinkevičius, S.; Yang, J.; Gaska, R.; Shatalov, M.; Shur, M.S. Optical studies of degradation of AlGaN quantum well based deep ultraviolet light emitting diodes. J. Appl. Phys. 2010, 108, 093113. [CrossRef]

9. Trivellin, N.; Monti, D.; De Santi, C.; Buffolo, M.; Meneghesso, G.; Zanoni, E.; Meneghini, M. Current induced degradation study on state of the art DUV LEDs. Microelectron. Reliab. 2018, 88-90, 868-872. [CrossRef]

10. Su, M.; Zhu, X.; Guo, Q.; Chen, Z.; Deng, S.; Chen, Z.; Wang, Y.; Deng, J.; Sun, W. Characterization and simulation of 280 nm UV-LED degradation. AIP Adv. 2021, 11, 035315. [CrossRef]

11. Meneghesso, G.; Levada, S.; Zanoni, E.; Podda, S.; Mura, G.; Vanzi, M.; Cavallini, A.; Castaldini, A.; Du, S.; Eliashevich, I. Failure modes and mechanisms of DC-aged GaN LEDs. Phys. Status Solidi Appl. Res. 2002, 194, 389-392. [CrossRef]

12. Ma, Z.; Cao, H.; Lin, S.; Li, X.; Zhao, L. Degradation and failure mechanism of AlGaN-based UVC-LEDs. Solid. State. Electron. 2019, 156, 92-96. [CrossRef]

13. Zhang, H.; Zhang, W.; Zhang, S.; Shan, M.; Zheng, Z.; Wang, A.; Xu, L.; Wu, F.; Dai, J.; Chen, C. Improved Reliability of AlGaN-Based Deep Ultraviolet LED with Modified Reflective N-Type Electrode. IEEE Electron Device Lett. 2021, 42, 978-981. [CrossRef]

14. Lu, C.C.; Wang, C.P.; Liu, C.Y.; Hsu, C.P. The Efficiency and Reliability Improvement by Utilizing Quartz Airtight Packaging of UVC LEDs. IEEE Trans. Electron Devices 2016, 63, 3143-3146. [CrossRef]

15. Amano, H.; Collazo, R.; De Santi, C.; Einfeldt, S.; Funato, M.; Glaab, J.; Hagedorn, S.; Hirano, A.; Hirayama, H.; Ishii, R.; et al. The 2020 UV emitter roadmap. J. Phys. D Appl. Phys. 2020, 53, 503001. [CrossRef]

16. Dal Lago, M.; Meneghini, M.; Trivellin, N.; Meneghesso, G.; Zanoni, E. Degradation mechanisms of high-power white LEDs activated by current and temperature. Microelectron. Reliab. 2011, 51, 1742-1746. [CrossRef]

17. Hsu, T.C.; Teng, Y.T.; Yeh, Y.W.; Fan, X.; Chu, K.H.; Lin, S.H.; Yeh, K.K.; Lee, P.T.; Lin, Y.; Chen, Z.; et al. Perspectives on UVC LED: Its progress and application. Photonics 2021, 8, 196. [CrossRef]

18. Sun, H.; Shakfa, M.K.; Muhammed, M.M.; Janjua, B.; Li, K.-H.; Lin, R.; Ng, T.K.; Roqan, I.S.; Ooi, B.S.; Li, X. Surface-Passivated AlGaN Nanowires for Enhanced Luminescence of Ultraviolet Light Emitting Diodes. ACS Photonics 2018, 5, 964-970. [CrossRef]

19. Chen, P.-W.; Hsiao, P.-W.; Chen, H.-J.; Lee, B.-S.; Chang, K.-P.; Yen, C.-C.; Horng, R.-H.; Wuu, D.-S. On the mechanism of carrier recombination in downsized blue micro-LEDs. Sci. Rep. 2021, 11, 22788. [CrossRef]

20. Sheremet, V.; Genç, M.; Gheshlaghi, N.; Elçi, M.; Sheremet, N.; Aydınlı, A.; Altuntaş, I.; Ding, K.; Avrutin, V.; Özgür, Ü.; et al Two-step passivation for enhanced InGaN/GaN light emitting diodes with step graded electron injectors. Superlattices Microstruct. 2018, 113, 623-634. [CrossRef]

21. Trivellin, N.; Meneghini, M.; Buffolo, M.; Meneghesso, G.; Zanoni, E. Failures of LEDs in Real-World Applications: A Review. IEEE Trans. Device Mater. Reliab. 2018, 18, 391-396. [CrossRef]

22. Meneghini, M.; Tazzoli, A.; Mura, G.; Meneghesso, G.; Zanoni, E. A Review on the Physical Mechanisms That Limit the Reliability of GaN-Based LEDs. IEEE Trans. Electron Devices 2010, 57, 108-118. [CrossRef]

23. Meneghini, M.; De Santi, C.; Tibaldi, A.; Vallone, M.; Bertazzi, F.; Meneghesso, G.; Zanoni, E.; Goano, M. Thermal droop in III-nitride based light-emitting diodes: Physical origin and perspectives. J. Appl. Phys. 2020, 127, 211102. [CrossRef]

24. De Santi, C.; Meneghini, M.; La Grassa, M.; Trivellin, N.; Galler, B.; Zeisel, R.; Hahn, B.; Goano, M.; Dominici, S.; Mandurrino, M.; et al. Thermal droop in InGaN-based LEDs: Physical origin and dependence on material properties. In Proceedings of the SPIE-The International Society for Optical Engineering, San Francisco, CA, USA, 13-18 February 2016; Volume 9768.

25. Trivellin, N.; Monti, D.; Piva, F.; Buffolo, M.; De Santi, C.; Zanoni, E.; Meneghesso, G.; Meneghini, M. Degradation processes of $280 \mathrm{~nm}$ high power DUV LEDs: Impact on parasitic luminescence. Jpn. J. Appl. Phys. 2019, 58, SCCC19. [CrossRef]

26. Morkoc, H. Handbook of Nitride Semiconductors and Devices. Volume 1, Materials, Properties, Physics and Growth; Wiley-VCH: Weinheim, Germany, 2008; ISBN 9783527628469.

27. Kim, K.-S.; Han, D.-P.; Kim, H.-S.; Shim, J.-I. Analysis of dominant carrier recombination mechanisms depending on injection current in InGaN green light emitting diodes. Appl. Phys. Lett. 2014, 104, 091110. [CrossRef]

28. Buffolo, M.; Magri, A.; De Santi, C.; Meneghesso, G.; Zanoni, E.; Meneghini, M. Gradual Degradation of InGaAs LEDs: Impact on Non-Radiative Lifetime and Extraction of Defect Characteristics. Materials 2021, 14, 1114. [CrossRef]

29. Monti, D.; De Santi, C.; Da Ruos, S.; Piva, F.; Glaab, J.; Rass, J.; Einfeldt, S.; Mehnke, F.; Enslin, J.; Wernicke, T.; et al. HighCurrent Stress of UV-B (In)AlGaN-Based LEDs: Defect-Generation and Diffusion Processes. IEEE Trans. Electron Devices 2019, 66, 3387-3392. [CrossRef]

30. De Santi, C.; Monti, D.; Dalapati, P.; Meneghini, M.; Meneghesso, G.; Zanoni, E. Reliability of Ultraviolet Light-Emitting Diodes; Springer: Cham, Switzerland, 2019; pp. 397-424. ISBN 9783319992112.

31. Reshchikov, M.A. Measurement and analysis of photoluminescence in GaN. J. Appl. Phys. 2021, 129, 121101. [CrossRef] 